\title{
Size-controlled and redox-responsive supramolecular nanoparticles
}

\author{
Raquel Mejia-Ariza ${ }^{\ddagger}$, Gavin A. Kronig ${ }^{\ddagger}$ and Jurriaan Huskens ${ }^{\star} \S$
}

\author{
Full Research Paper \\ Address: \\ Molecular NanoFabrication group, MESA+ Institute for \\ Nanotechnology University of Twente, P.O. Box 217, 7500 AE \\ Enschede, The Netherlands \\ Email: \\ Jurriaan Huskens ${ }^{*}$ - J.Huskens@utwente.nl \\ * Corresponding author $\ddagger$ Equal contributors \\ $\S$ Homepage: http://www.utwente.nl/tnw/mnf/ \\ Keywords: \\ host-guest interactions; nanoparticles; self-assembly; \\ stimulus-responsive; supramolecular chemistry
}

\author{
Beilstein J. Org. Chem. 2015, 11, 2388-2399. \\ doi:10.3762/bjoc. 11.260 \\ Received: 28 August 2015 \\ Accepted: 20 November 2015 \\ Published: 01 December 2015 \\ This article is part of the Thematic Series "Superstructures with \\ cyclodextrins: Chemistry and applications III". \\ Guest Editor: G. Wenz \\ (C) 2015 Mejia-Ariza et al; licensee Beilstein-Institut. \\ License and terms: see end of document.
}

\begin{abstract}
Control over the assembly and disassembly of nanoparticles is pivotal for their use as drug delivery vehicles. Here, we aim to form supramolecular nanoparticles (SNPs) by combining advantages of the reversible assembly properties of SNPs using host-guest interactions and of a stimulus-responsive moiety. The SNPs are composed of a core of positively charged poly(ethylene imine) grafted with $\beta$-cyclodextrin $(\mathrm{CD})$ and a positively charged ferrocene $(\mathrm{Fc})$-terminated poly(amidoamine) dendrimer, with a monovalent stabilizer at the surface. Fc was chosen for its loss of CD-binding properties when oxidizing it to the ferrocenium cation. The ionic strength was shown to play an important role in controlling the aggregate growth. The attractive supramolecular and repulsive electrostatic interactions constitute a balance of forces in this system at low ionic strengths. At higher ionic strengths, the increased charge screening led to a loss of electrostatic repulsion and therefore to faster aggregate growth. A Job plot showed that a 1:1 stoichiometry of host and guest moieties gave the most efficient aggregate growth. Different stabilizers were used to find the optimal stopper to limit the growth. A weaker guest moiety was shown to be less efficient in stabilizing the SNPs. Also steric repulsion is important for achieving SNP stability. SNPs of controlled particle size and good stability (up to seven days) were prepared by finetuning the ratio of multivalent and monovalent interactions. Finally, reversibility of the SNPs was confirmed by oxidizing the Fc guest moieties in the core of the SNPs.
\end{abstract}

\section{Introduction}

Self-assembly and molecular recognition are two core concepts underlying supramolecular chemistry. These offer convenient and versatile pathways to nanostructured materials composed of molecular building blocks [1]. This fabrication strategy has been used to form supramolecular nanoparticles (SNPs) in which multiple copies of different building blocks interact via 
specific, non-covalent interactions [2]. They have the potential to be used in biomedical applications owing to control over their size, their assembly/disassembly, and the modular character for the versatile incorporation of agents aiming for imaging [3], photothermal therapy [4], drug delivery [5-7] and gene delivery [8-10] applications.

Different approaches have been used to form SNPs. Davis et al. showed the formation of SNPs using attractive electrostatic interactions between positively charged $\beta$-cyclodextrin (CD)containing polymers and negatively charged siRNA at the core [8]. Neutral adamantyl-grafted poly(ethylene glycol) (Ad-PEG) was incorporated at the surface to stabilize these SNPs using host-guest interactions between CD and Ad. Tseng et al. studied the formation of SNPs that are assembled solely by host-guest interactions $[11,12]$. Here, the core is composed of multivalent interactions between positively charged CD-grafted polymers and positively charged poly(amidoamine) (PAMAM) dendrimers, and a monovalent neutral Ad-PEG stopper is introduced at the surface for stabilization. The SNP size was increased by increasing the amount of multivalent guest molecules in the core, while keeping the host and stopper concentration constant and having an excess of stopper to avoid precipitation. Wintgens et al. showed the formation of SNPs by controlling the host-guest ratio and the total concentration of components with a neutral polymer backbone [13]. Recently, our group $[2,14,15]$ formed SNPs by varying the ratio of neutral monovalent stoppers and multivalent, positively charged guest dendrimer. Here, the overall concentration of the building blocks was kept constant while maintaining an equimolar stoichiometry of host and guest moieties. Moreover, our group [16] showed that SNP formation is controlled by a balance of forces between attractive supramolecular and repulsive electrostatic interactions using a multicomponent system based on a linear, negatively charged polymer. The force balance used in the latter approach was only observed with negatively charged polymers at low ionic strengths, and it is not known whether this balance occurs also for positively charged polymers and dendrimers.

In order to use these SNPs for biomedical applications, in particular for drug delivery, a stimulus-responsive self-assembled system is desired for controlled cargo release. Ferrocene $(\mathrm{Fc})$ is a ubiquitous redox-responsive molecule that is associated with a reversible one-electron oxidation to the ferrocenium cation. At the same time, in its reduced state, $\mathrm{Fc}$ is a good guest for $\mathrm{CD}$, but the affinity for $\mathrm{CD}$ is practically completely lost upon oxidation [17]. Thus, the formed CD-Fc inclusion complex disassembles when the Fc moiety is converted to the ferrocenium cation by electrochemistry [18] or by adding an oxidizing agent [19]. Different studies have employed this concept to form redox-responsive systems applied, for example, in self-healing materials [19], polymeric hydrogels [20,21], voltage-responsive vesicles [22], ultrasentive enzyme sensors [23], and as a plasma membrane protein isolation method [24]. So far, this concept has not been applied to SNPs.

Here, we aim to make SNPs with a redox-switchable assembly/ disassembly mechanism. As a proof of concept, we used positively charged CD-grafted poly(ethylene imine) (CD-PEI) as a host, positively charged ferrocene-terminated PAMAM ( $\mathrm{Fc}_{8}$-PAMAM) dendrimer as the multivalent guest and a monovalent stabilizer. Different stabilizers were used such as: Ad-PEG, Fc-terminated poly(ethylene glycol) (Fc-PEG), methoxypoly(ethylene glycol) (mPEG), and Ad-tetraethylene glycol (Ad-TEG). The effect of the following parameters on the formation of these SNPs is investigated: the role of ionic strength on SNP formation, the role of host-guest stoichiometry on the growth rate of the SNPs, and the influence of the affinity of the guest moiety and that of the PEG length of the stabilizer on the SNP stability. The size of the SNPs is controlled by the stoichiometry of the multivalent guest and the monovalent stabilizer. Finally, the reversibility of the SNPs is assessed by studying the influence of oxidation of the Fc moieties.

\section{Results and Discussion Characterization of building blocks}

The positively charged host CD-PEI was synthesized according to earlier reports with slight modifications $[25,26]$. A reaction between 6-monotosyl- $\beta$-cyclodextrin (TsCD) and PEI in DMSO was performed using an excess of triethylamine as a base, followed by purification by dialysis. In order to control the stoichiometry of the host and guest moieties, the number of CDs per PEI was determined using microcalorimetry and NMR. According to the ${ }^{1} \mathrm{H}$ NMR spectrum, the PEI backbone in the polymer building block CD-PEI is functionalized with, on average, $8 \mathrm{CD}$ units. To assess the $\mathrm{CD}$ concentration in a CD-PEI stock solution, a calorimetric titration was performed using CD-PEI as the host and Ad-TEG as a guest, as shown in Figure 1a. Fitting the results by optimizing $\Delta H^{\circ}, K$ and the CD host concentration gave a concentration of $0.39 \mathrm{mg} / \mathrm{mL}$ of CD-PEI, which is equivalent to a concentration of $0.088 \mathrm{mM}$ of $\mathrm{CD}$ moieties participating in host-guest interactions. The results gave a binding constant $\left(K_{\mathrm{a}}\right)$ of $3 \times 10^{4} \mathrm{~L} \mathrm{~mol}^{-1}$. This is slightly lower than the interaction between native CD and Ad-TEG, for which a $K_{\mathrm{a}}$ value of $5 \times 10^{4} \mathrm{~L} \mathrm{~mol}^{-1}$ has been determined (see Figure 1b). It can therefore be concluded that the grafting of CD to PEI has a minor effect on the host-guest binding affinity.

The positively charged $\mathrm{Fc}_{8}$-PAMAM multivalent guest was prepared according to a procedure developed in our group [27]. The positively charged Ad-terminated PAMAM ( $\mathrm{Ad}_{8}-$ 

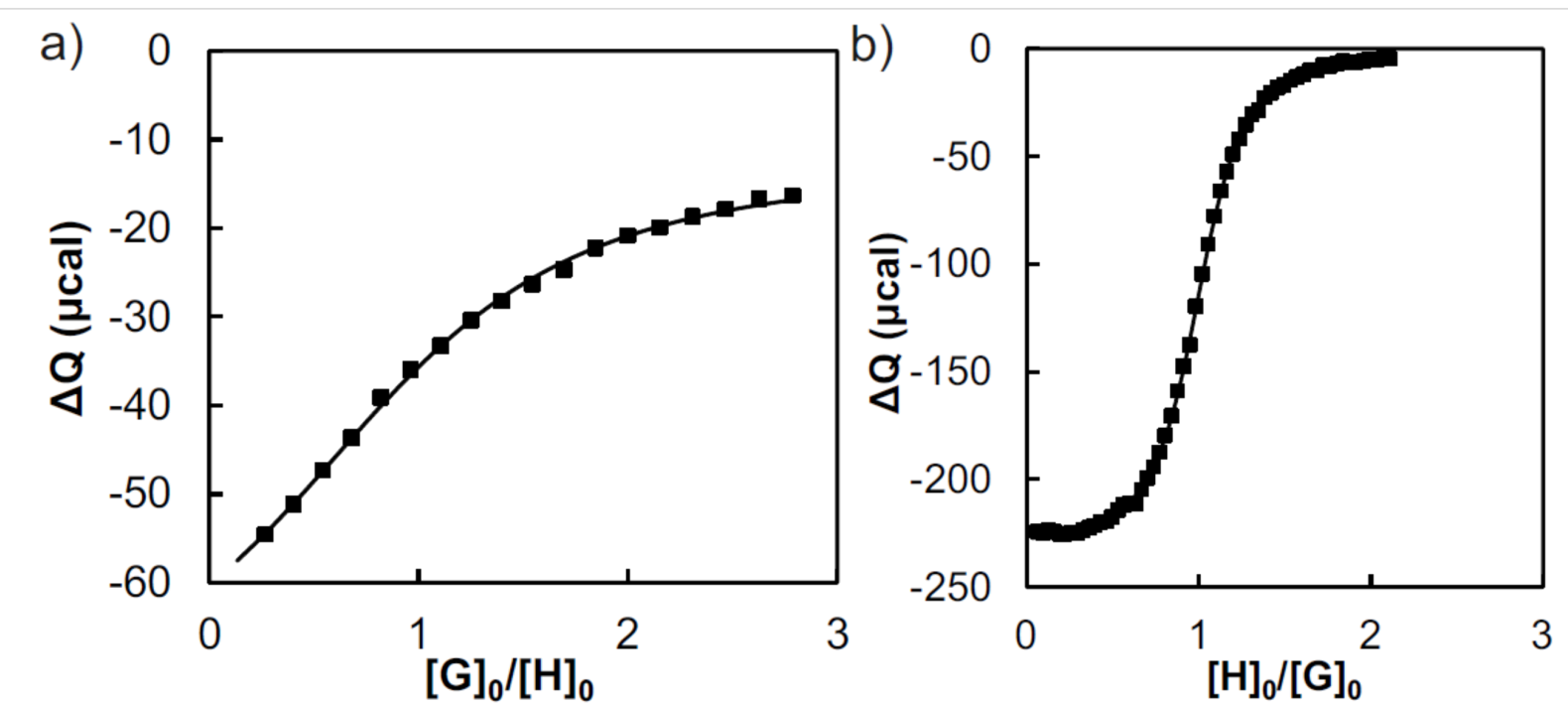

Figure 1: Microcalorimetric titrations of a) CD-PEI (CD concentration of $0.088 \mathrm{mM}$, cell) with Ad-TEG (1.1 mM, burette) and b) Ad-TEG (1.1 mM, cell) with $C D(10 \mathrm{mM}$; burette). $\mathrm{H}=$ host (CD from CD-PEI or native $C D)$ and $\mathrm{G}=$ guest (Ad from Ad-TEG). Experimental binding curve (markers) and best fit to a $1: 1$ model (line).

PAMAM), used as a control, was prepared according to a literature procedure [11]. The neutral Fc-PEG stabilizer was synthesized by a reaction of 1-(chlorocarbonyl)ferrocene with the terminal amino group of methoxypoly(ethylene glycol)amine $\left(M_{\mathrm{w}}=5000 \mathrm{~g} / \mathrm{mol}\right)$ in dichloromethane, using an excess of triethylamine as a base, followed by precipitation from diethyl ether. To evaluate the association constant of the Fc moiety with free $\mathrm{CD}$, and to confirm the degree of functionalization, a calorimetric titration was performed with native $\mathrm{CD}$, as shown in Figure 2. This titration confirmed that nearly $100 \%$ of Fc-PEG was formed. The $K_{\mathrm{a}}$ of Fc-PEG with native CD is $1.2 \times 10^{3} \mathrm{~L} \mathrm{~mol}^{-1}$, which is comparable to the binding constant of Fc dendrimers with $\mathrm{CD}$ [28].

The neutral stabilizer Ad-PEG was synthesized according to a literature procedure [11], by the reaction of 1-adamantylamine with the succinimidyl ester of carboxymethyl-PEG $\left(M_{\mathrm{W}}=5000 \mathrm{~g} / \mathrm{mol}\right)$ in dichloromethane with an excess of triethylamine.

\section{Formation and size control of SNPs}

Scheme 1a shows the concept of forming SNPs based on host-guest interactions, and the possible or impossible redoxinduced disassembly when using Fc or Ad as the guest moiety, respectively. Throughout this study, concentrations of all the building blocks were expressed as the molar concentrations of the monovalent host and guest moieties, i.e., $\mathrm{CD}$, Ad and Fc.

\section{Influence of the ionic strength}

The SNPs used here are formed using host-guest interactions between $\mathrm{Fc}_{8}$-PAMAM and CD-PEI. These molecules have

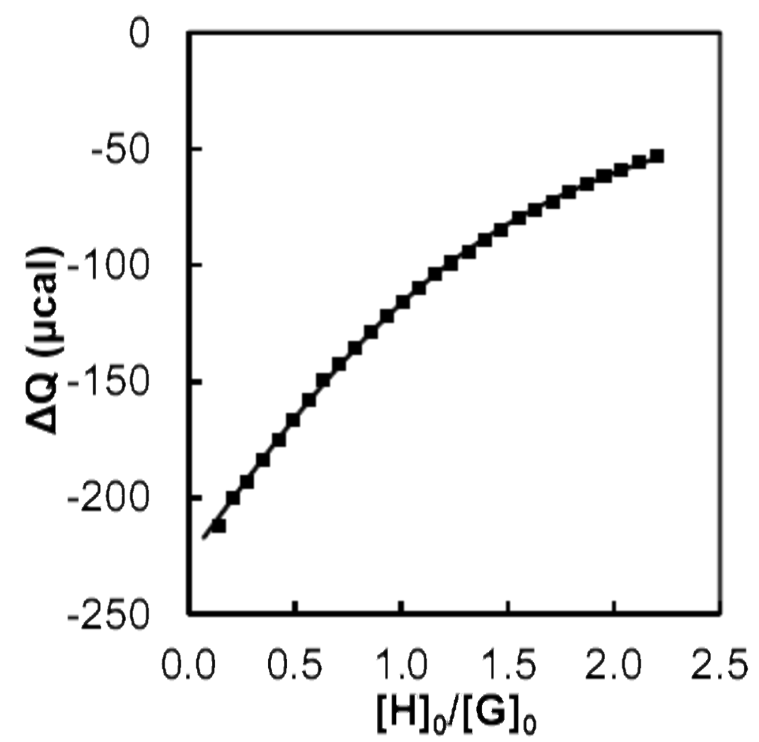

Figure 2: ITC titration of FC-PEG (1.03 mM; cell) with native CD (10 mM; burette). $\mathrm{H}=$ host and $\mathrm{G}=$ guest. Experimental binding curve (markers) and best fit to a 1:1 model (line).

positive charges that can influence the growth by repulsive interactions, which is an additional parameter that can influence the formation of SNPs. Moreover, Fc is used as the guest moiety as its stimulus-responsive properties lead to a triggered assembly/disassembly system. In order to study the influence of ionic strength on SNP formation, we used 0 to $0.2 \mathrm{M} \mathrm{NaCl}$ solutions and different guest-host ratios when assembling SNPs from $\mathrm{CD}$-PEI and $\mathrm{Fc}_{8}$-PAMAM in the absence of stabilizer. SNPs were formed by adding $\mathrm{Fc}_{8}$-PAMAM (dissolved in 


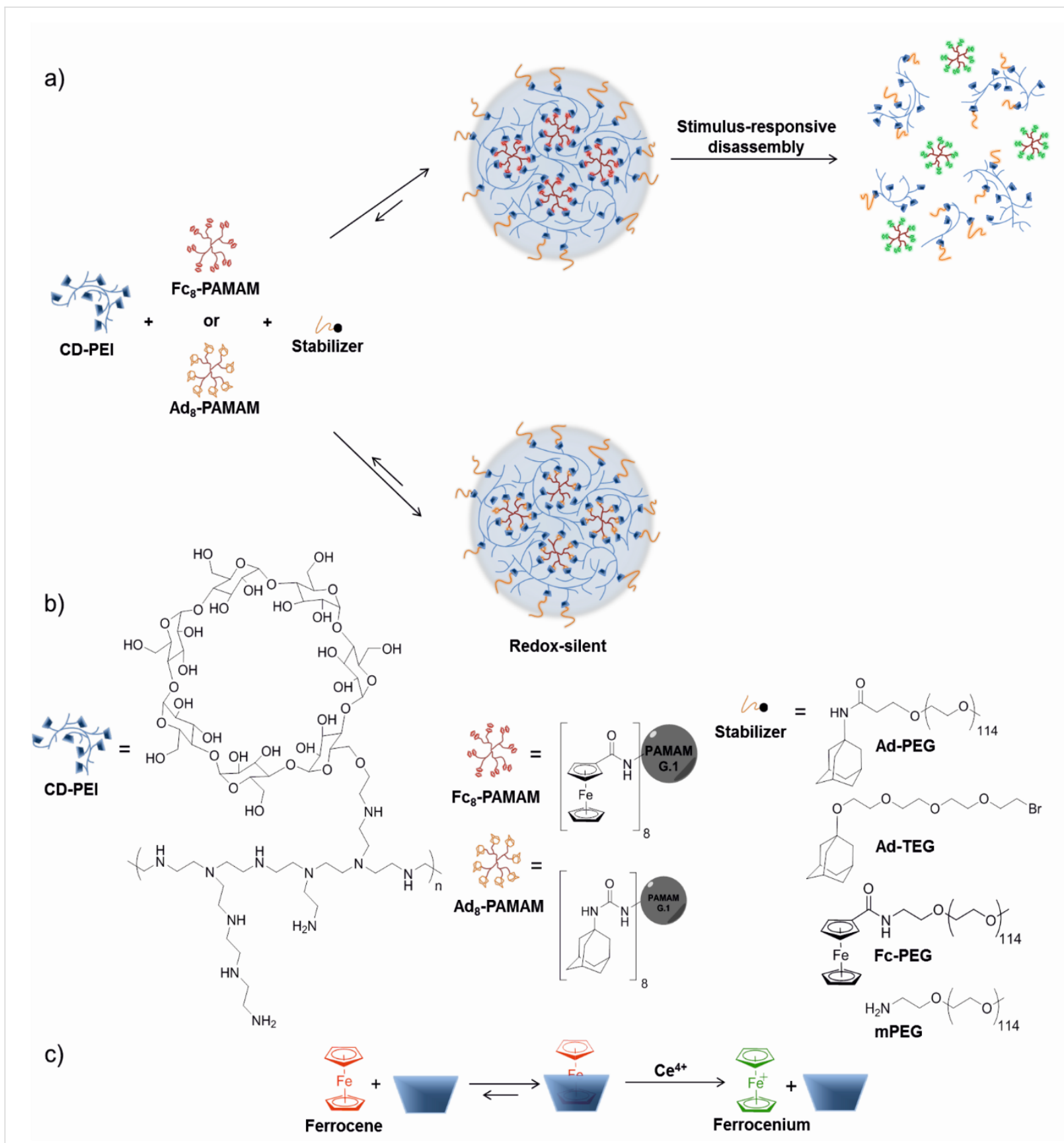

Scheme 1: a) Schematic representation of the supramolecular nanoparticle (SNP) self-assembly and redox-triggered disassembly of the host-guest complex. b) Chemical structures of the building blocks used here. c) Binding of Fc by $\mathrm{CD}$ and subsequent dissociation upon oxidation of Fc.

DMSO) to an aqueous solution of CD-PEI $([C D]=100 \mu \mathrm{M})$ in aqueous $\mathrm{NaCl}$ solution. To confirm particle formation, SNPs were characterized using DLS and SEM (Figure 3). DLS measurements of the particles in water without salt showed nanoparticles of comparable hydrodynamic diameters $(d)$ for the different $\mathrm{Fc} / \mathrm{CD}$ ratios. The size for $0 \% \mathrm{Fc}$ (only $\mathrm{CD}-\mathrm{PEI}$ ) was approx. $70 \mathrm{~nm}$, which is attributed to the fact that the concentration of CD-PEI is above its critical aggregation concentration. These results show that the particle size remains similar for the range of $\mathrm{Fc} / \mathrm{CD}$ ratios shown here (in the absence of salt).

Similar experiments were performed at three different salt concentrations, $0.1,0.15$ and $0.2 \mathrm{M} \mathrm{NaCl}$, while keeping $[C D]=100 \mu \mathrm{M}$. Particle formation and growth was observed by DLS after $20 \mathrm{~min}$ and $3 \mathrm{~h}$. Figure 4 shows an increase of particle size with increasing salt concentration at ionic strengths above $0.1 \mathrm{M}$, and the effect is stronger after $3 \mathrm{~h}$, indicating 
a)

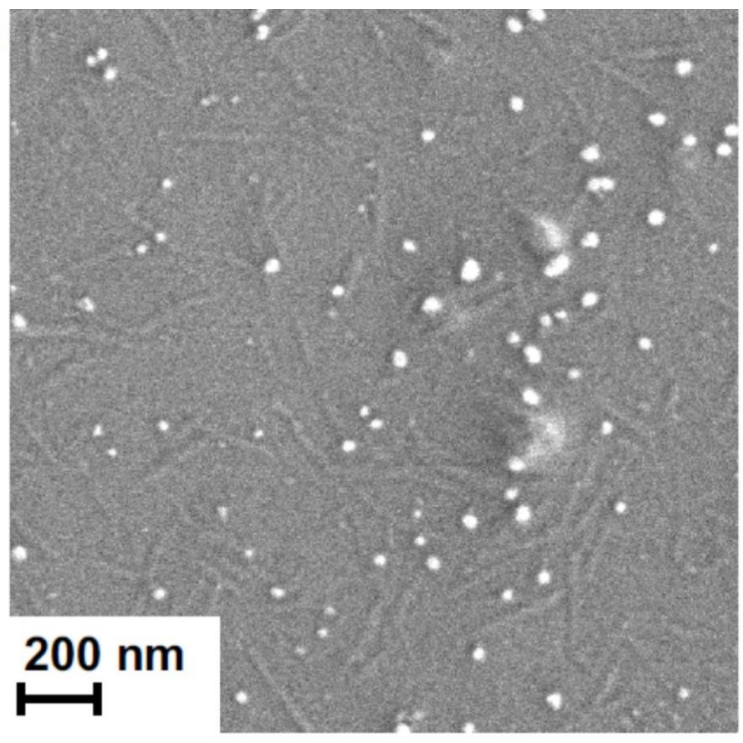

c)

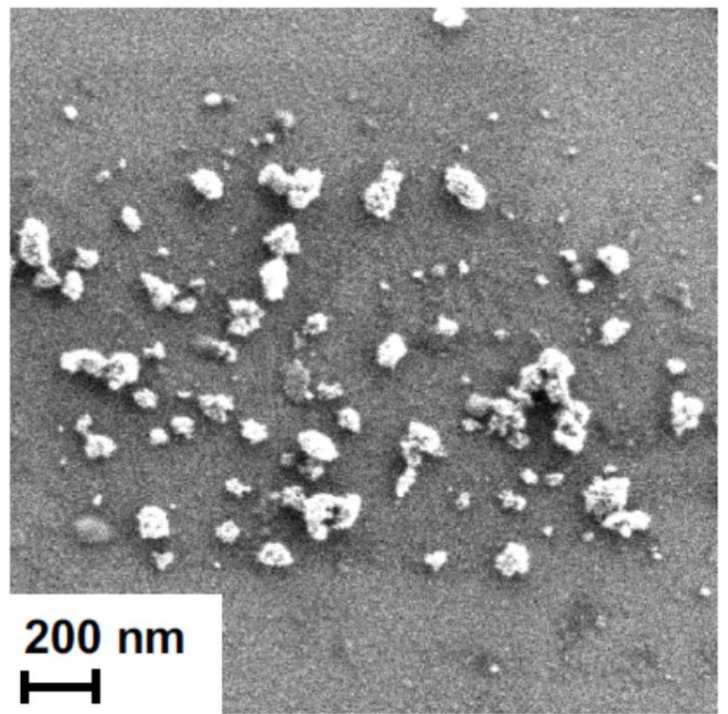

b)

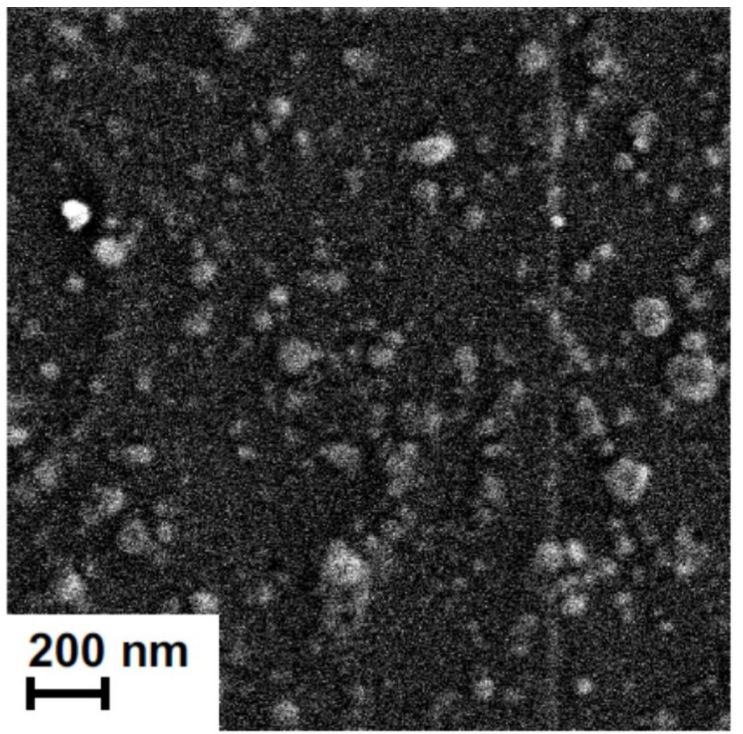

d)

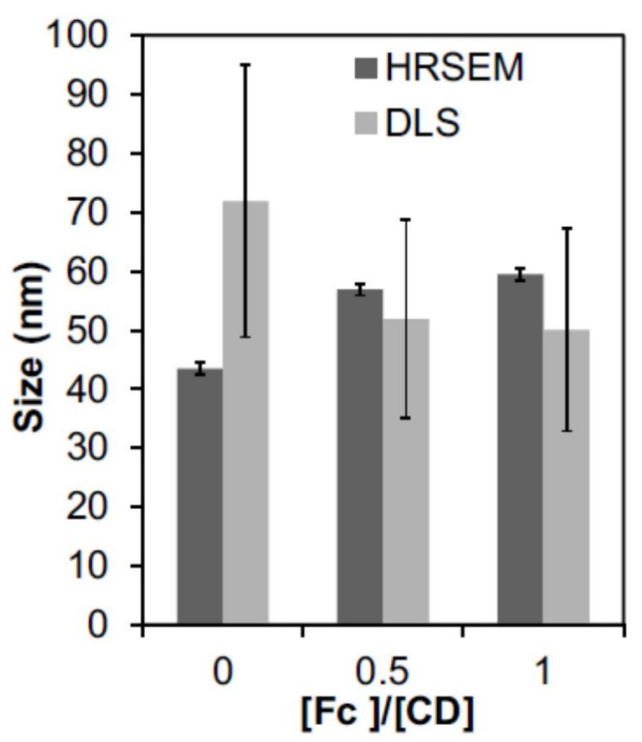

Figure 3: Size determination of SNPs prepared from CD-PEI and $\mathrm{FC}_{8}-\mathrm{PAMAM}$ : SEM images $(\mathrm{a}-\mathrm{C})$ of the resulting SNPs as a function of the [Fc]/[CD] ratio (in Fc and $\mathrm{CD}$ moieties from $\mathrm{Fc}_{8}$-PAMAM and $\mathrm{CD}-\mathrm{PEI}$, respectively) in aqueous solution (without salt) (a: 0 , b: 0.5 and $\mathrm{c}: 1$ ) used during supramolecular assembly keeping constant the total concentration using $[C D]=100 \mu \mathrm{M}$ and $d$ ) $d$ by DLS and size by HRSEM.

a slow growth process. Up to an ionic strength of $0.1 \mathrm{M}$, however, no change of particle size was apparent.

Both host-guest and electrostatic interactions are at play here. Cyclodextrin host-guest interactions are largely hydrophobic in nature, and their affinity tends to increase slightly at increasing ionic strength. However, because of the already strong and multivalent nature $[27,28]$ of the host-guest interactions at low ionic strengths, we do not expect such affinity differences to lead to the drastic stability differences observed here between the ionic strengths of 0.10 and $0.15 \mathrm{M}$. Regarding the electrostatic interactions, the Debye screening length is reduced to approx. $1 \mathrm{~nm}$ when increasing the ionic strength to $0.1 \mathrm{M}$. Moreover, zeta potential $(\zeta)$ measurements were performed using $[\mathrm{CD}]=100 \mu \mathrm{M}$ (CD is the number of moieties from $\mathrm{CD}-\mathrm{PEI})$ and $[\mathrm{Fc}]=50 \mu \mathrm{M}(\mathrm{Fc}$ is the number of moieties from $\mathrm{Fc}_{8}$-PAMAM) at different salt concentrations after $20 \mathrm{~min}$, as shown in Table $1 . \zeta$ decreased at increased ionic strengths, and values below $20 \mathrm{mV}$ were observed at ionic strengths of $0.1 \mathrm{M}$ and higher, indicating an absence of colloidal stabilization by charge repulsion at high ionic strength. These results demonstrate, as shown before for negatively charged polymers [16], that the aggregation is due to a loss of electrostatic colloidal stabilization. Thus, a balance between repulsive electrostatic 

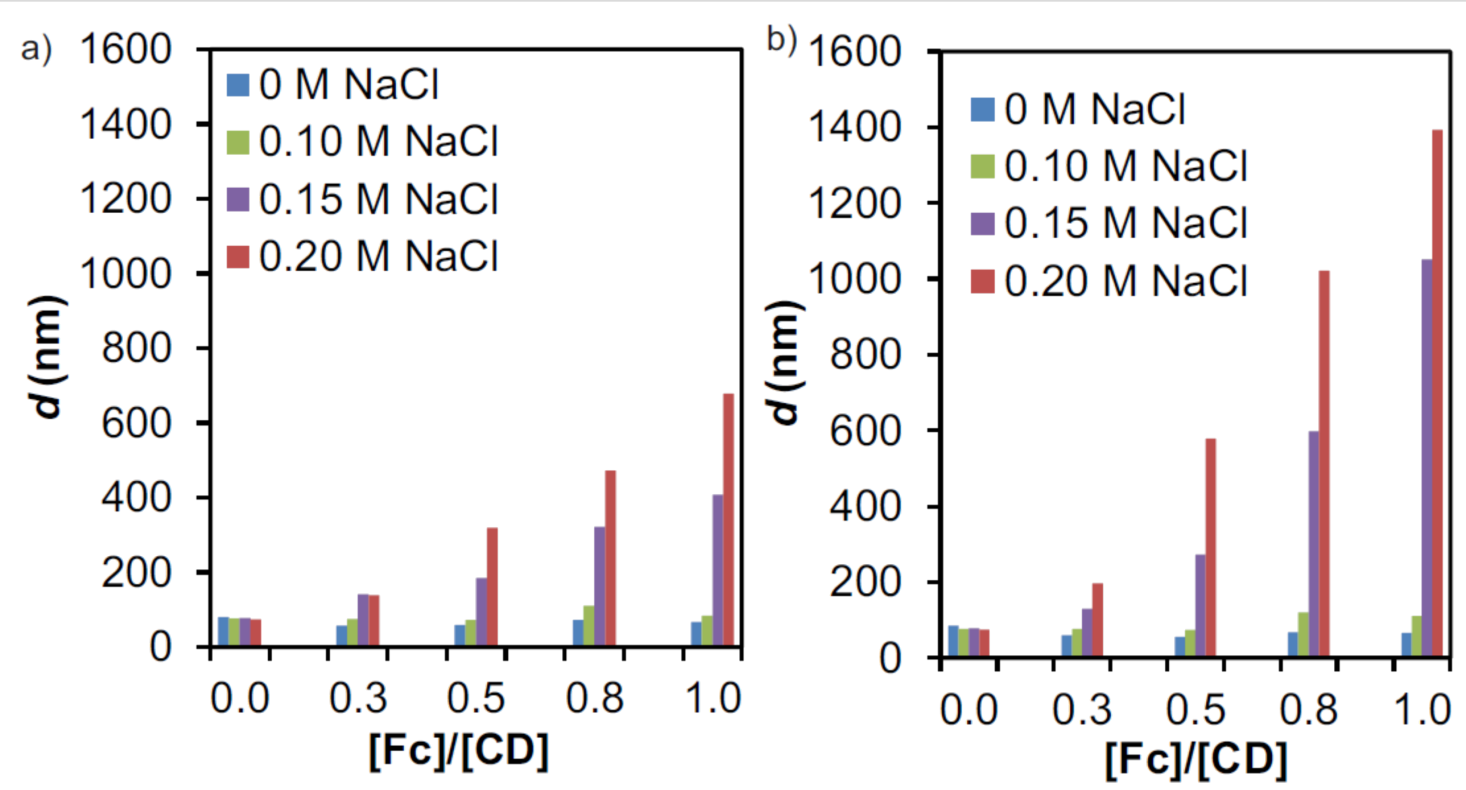

Figure 4: DLS size determination of SNPs prepared from CD-PEl and $\mathrm{Fc}_{8}-\mathrm{PAMAM}$ by increasing the [Fc]/[CD] ratio (in $\mathrm{Fc}$ and $\mathrm{CD}$ moieties from $\mathrm{F} \mathrm{C}_{8}$ PAMAM and CD-PEI, respectively) at different salt concentrations $(0-0.2 \mathrm{M} \mathrm{NaCl})$ keeping constant the total concentration using $[C D]=100 \mu \mathrm{M}$ after: a) 20 min and b) $3 \mathrm{~h}$.

forces and attractive host-guest interactions exists at low ionic strengths, leading to stable SNPs even in the absence of a stabilizer. At higher ionic strengths, however, the increased charge screening leads to a loss of electrostatic repulsion and therefore to aggregates that grow over time.

Table 1: Hydrodynamic diameters, $d$, and zeta potentials, $\zeta$, measured by DLS of SNPs prepared at increasing salt concentrations $(0-0.2 \mathrm{M}$ $\mathrm{NaCl}$ ) using $\mathrm{CD}-\mathrm{PEI}$ and $\mathrm{Fc}_{8}$-PAMAM keeping the total concentration constant at $[C D]=100 \mu \mathrm{M}$ and $[\mathrm{FC}]=50 \mu \mathrm{M}$ (in Fc and CD moieties from $\mathrm{Fc}_{8}$-PAMAM and CD-PEI, respectively).

\begin{tabular}{ccc} 
salt concentration $(\mathrm{M})$ & $d(\mathrm{~nm})$ & $\zeta(\mathrm{mV})$ \\
\hline 0 & 51 & 33 \\
0.1 & 58 & 17 \\
0.15 & 247 & 15 \\
0.20 & 441 & 15
\end{tabular}

\section{Influence of the host-guest stoichiometry on SNP formation}

To assess whether all host and guest moieties of CD-PEI and $\mathrm{Fc}_{8}$-PAMAM are engaged in interactions, a Job plot was performed by varying the host-guest ratio while keeping the sum of the concentrations constant. The SNP growth at high ionic strength was used as a sign of interactions between the multivalent host and guest molecules. When increasing the Fc content to 0.5 (i.e., a host-guest ratio of $1: 1$ ), an increase in particle size was observed, but the particle size remained constant as the $\mathrm{Fc}$ concentration was increased further (data not shown). Therefore, $2 \mathrm{mM}$ of native $\mathrm{CD}$ was added in an attempt to suppress non-specific, hydrophobically driven aggregation at excess Fc moieties. Figure 5a shows, however, a very similar picture, with particle sizes increasing as the $\mathrm{Fc}$ fraction was raised from 0 to 0.5 , and a plateau of constant size at higher $\mathrm{Fc}$ fractions. Apparently, the addition of native CD was insufficient to cap excess free $\mathrm{Fc}$ groups, due to a lack of affinity. To verify that this low affinity is the main reason for the continued particle growth observed at Fc contents above 0.5, the Ad dendrimer analog was used as a control. Similar to the Fc case, increase of the Ad fraction up to 0.5 (see Figure 5b) led to an increase of the SNP size. Higher Ad contents in the presence of $2 \mathrm{mM}$ native $\mathrm{CD}$, however, led to a decrease in particle size, indicating that an excess of Ad is efficiently blocked by CD, which is in line with the approx. 30 times higher binding affinity of Ad (see above). Most importantly, this graph (Figure 5) confirms a 1:1 binding stoichiometry of the system. These results demonstrate that SNPs form optimally at a 1:1 stoichiometry at which all available host and guest moieties are simultaneously engaged in host-guest interactions.

\section{Effect of a monovalent stopper}

In order to limit particle growth and achieve stabilization, a proper stabilizing agent should be found. The strategy on stoichiometry remains the same as previously described, keeping the host-guest ratio at 1:1 and a high ionic strength of $0.2 \mathrm{M}$ $\mathrm{NaCl}$. Two different parameters were considered to study the effect of a stopper: length and binding affinity. The formation of SNPs was studied using constant concentrations of 

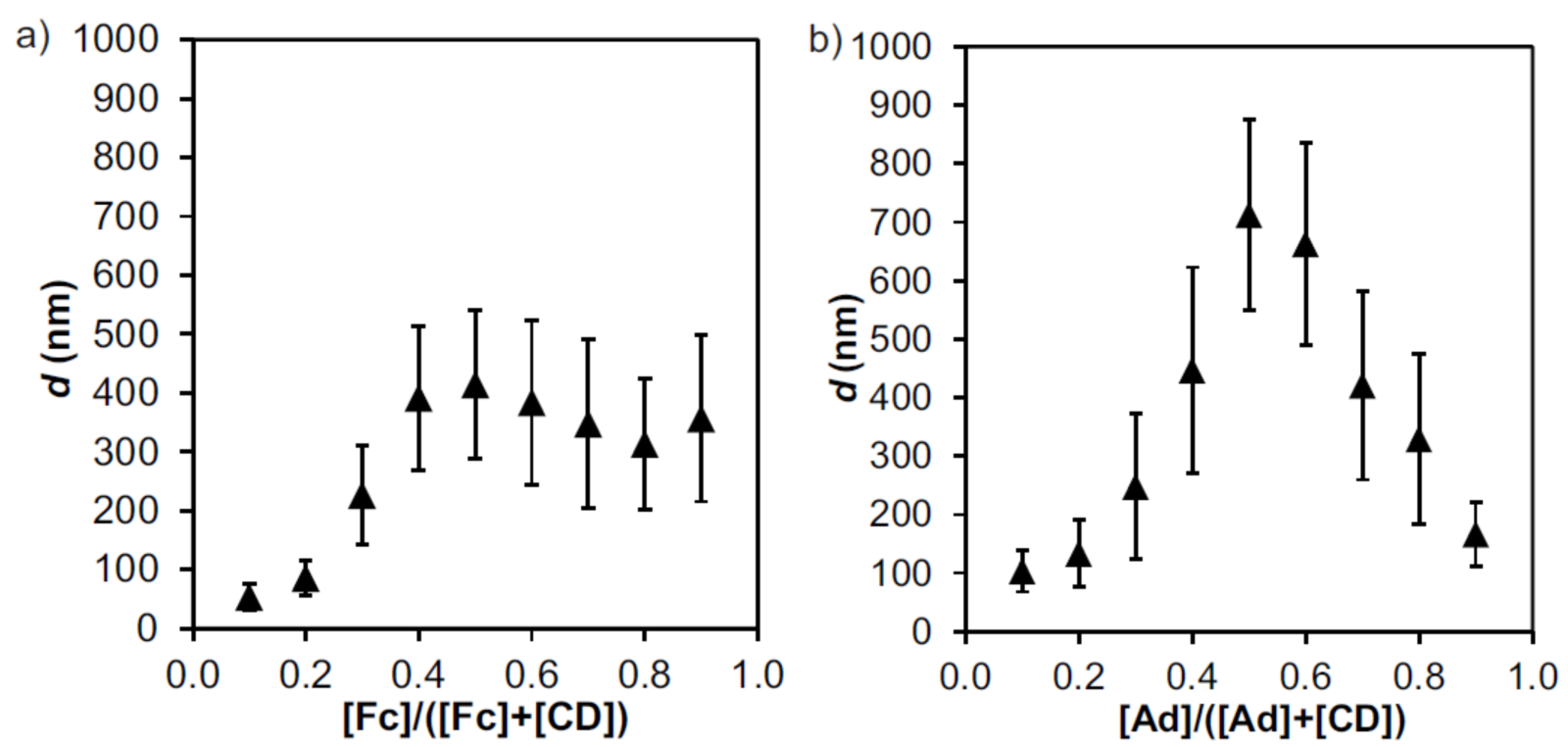

Figure 5: Hydrodynamic diameter, $d$, of SNPs prepared from CD-PEI and F $\mathrm{C}_{8}-\mathrm{PAMAM}$ or $\mathrm{Ad}_{8}-\mathrm{PAMAM}$ measured by DLS as a function of the [guest] $/\left(\left[\right.\right.$ guest] $+[\mathrm{CD}]$ ) ratio for: a) CD-PEI and $\mathrm{FC}_{8}$-PAMAM [CD $\left.+\mathrm{Fc}\right]=50 \mu \mathrm{M}$ (in CD and Fc moieties), $l=0.4 \mathrm{M} \mathrm{NaCl}$, with $2 \mathrm{mM}$ native $\mathrm{CD}$ measured after $10 \mathrm{~min}$, and b) CD-PEl and $\mathrm{Ad}_{8}$-PAMAM $[\mathrm{CD}+\mathrm{Ad}]=200 \mu \mathrm{M}$ (in CD and Ad moieties), $I=0.2 \mathrm{M} \mathrm{NaCl}$, with $2.0 \mathrm{mM}$ native $C D$ measured after $6 \mathrm{~min}$.

$[\mathrm{CD}]=100 \mu \mathrm{M}(\mathrm{CD}$ is the number of moieties from CD-PEI) and $[\mathrm{Fc}+$ guest-stabilizer $]=100 \mu \mathrm{M}(\mathrm{Fc}$ is the number of moieties from $\mathrm{Fc}_{8}$-PAMAM), thus keeping the molecular recognition moieties in a 1:1 stoichiometry ratio. For these experiments, first aqueous solutions of CD-PEI without or with a stabilizer (Ad-PEG, mPEG, Fc-PEG, Ad-TEG; see Scheme 1b) were prepared. Subsequently, $\mathrm{Fc}_{8}$-PAMAM (dissolved in DMSO) was injected into the respective aqueous solutions. Size tuning of the SNPs was assessed by using two different concentrations of $\mathrm{Fc}_{8}$-PAMAM dendrimers and stabilizer, while keeping the overall concentration of the guest moieties constant. The formation of SNPs was evaluated by DLS after $20 \mathrm{~min}$ and $4 \mathrm{~h}$. Figure 6 shows the strong effect of the use of a stabilizer on the SNP size and, as shown before, that the SNP size is further increased by increasing the fraction of multivalent Fc moieties at the core of the particles. These results show that the smallest sizes and most stable particles were formed when using Ad-PEG as the stabilizer. Larger particles were observed for Fc-PEG than for Ad-PEG, but these also appeared stable (sizes after $20 \mathrm{~min}$ and $4 \mathrm{~h}$ are similar). The shorter Ad-TEG was less efficient in capping and stabilizing the SNPs compared to polymeric Ad-PEG. Leaving out the guest moiety, by using mPEG as a stabilizer, led to uncontrolled growth as was also observed in the absence of PEG. It should be noted that polymeric PEG derivatives have a critical aggregation constant that can be well below $1 \mu \mathrm{M}$ [29]. We measured DLS for a $25 \mu \mathrm{M}$ solution Ad-PEG and observed particles with a size of approx. $85 \mathrm{~nm}$ (data not shown), and others have observed sizes of 20-30 nm for different PEG derivatives [29]. However, the sizes reported here (Figure 6) for SNPs are much larger, most likely caused by larger abundance of SNPs compared to PEG aggregates and the higher response of SNPs by DLS. In particular the high similarity of the hydrodynamic sizes between the control (using the non-interacting $\mathrm{mPEG}$ ) and the SNPs in the absence of stopper shows that the DLS data reported in Figure 6 are not convoluted by PEG aggregates. In summary, these results demonstrate that a guest moiety is important, and that a weaker guest is less efficient in stabilizing the particle. Moreover, steric repulsion by having a long polymer chain present on the stopper is important for achieving SNP stability.

\section{Size control by changing the stoichiometric composition}

SNP size control was achieved by changing the stoichiometry of the multivalent guest and the monovalent stabilizer while keeping the overall host-guest ratio constant and equimolar. SNPs were observed by SEM and DLS for all samples as shown in Figure 7. The particle sizes determined by SEM (see Figure $7 \mathrm{a}-\mathrm{c}$ ) with sizes of $49 \pm 13 \mathrm{~nm}$ (Fc fraction of 0.375$)$, $61 \pm 17 \mathrm{~nm}$ (Fc fraction of 0.5$)$ and $67 \pm 21 \mathrm{~nm}$ (Fc fraction of 0.625 ) were much smaller than those measured by DLS. This can be possibly due to drying effects. Figure $7 \mathrm{~d}-\mathrm{f}$ shows an increasing size with increasing fraction of the multivalent $\mathrm{Fc}_{8}-$ PAMAM and they are stable up to 7 days. In summary, we have demonstrated the formation of stable and size-tunable SNPs by varying the multivalent vs monovalent stoichiometry. 
a)

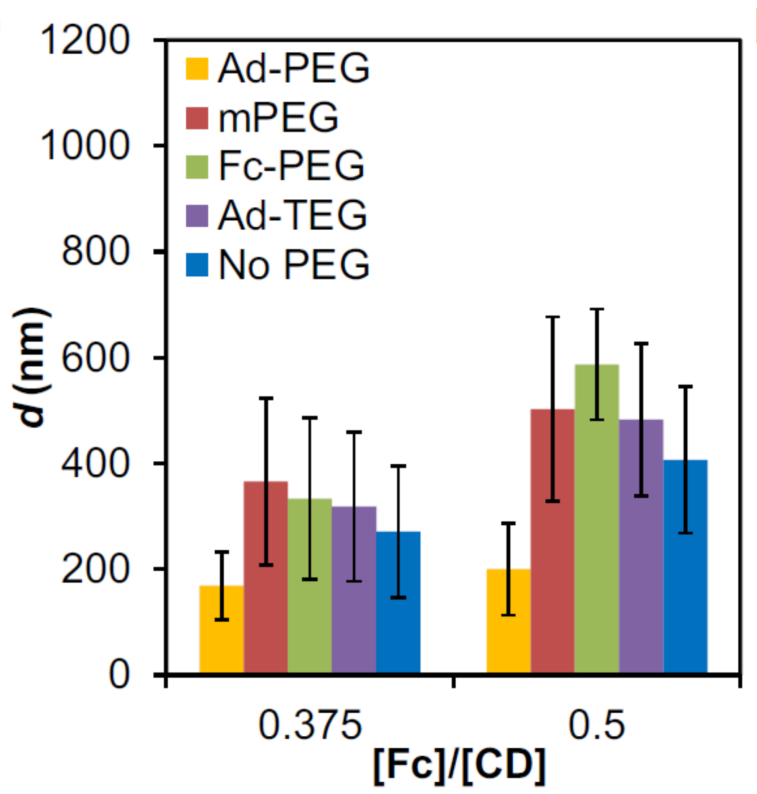

b)

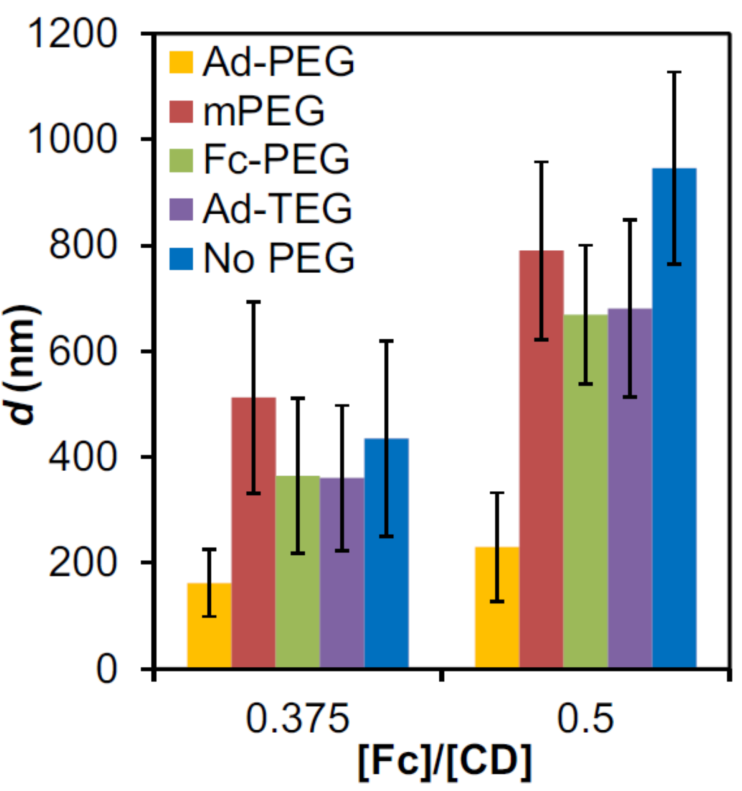

Figure 6: DLS size determinations of SNPs prepared from CD-PEI, F 8 -PAMAM, in the absence or presence of a monovalent stopper, for two $[\mathrm{Fc}] /[\mathrm{CD}]$ ratios (in Fc and $\mathrm{CD}$ moieties from $\mathrm{Fc}_{8}-\mathrm{PAMAM}$ and $\mathrm{CD}-\mathrm{PEI}$, respectively) keeping constant both $[\mathrm{CD}]=[\mathrm{Fc}]+[\mathrm{stopper}]=100 \mathrm{uM}$ (where [stopper] is the concentration of the monovalent stopper), using $0.2 \mathrm{M} \mathrm{NaCl}$ and different stoppers: Ad-PEG, mPEG (no guest moiety), Fc-PEG, Ad-TEG and without stabilizer after: a) $20 \mathrm{~min}$ and b) $4 \mathrm{~h}$.

a)

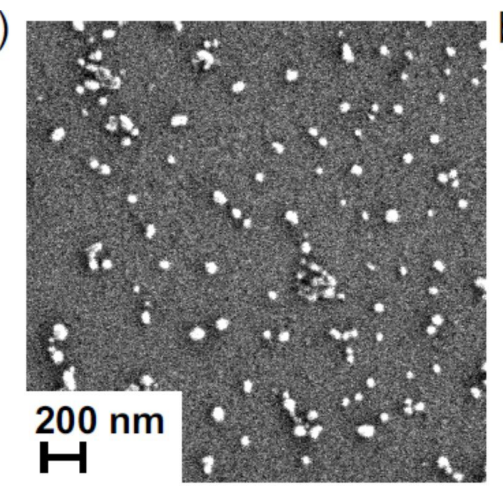

d)

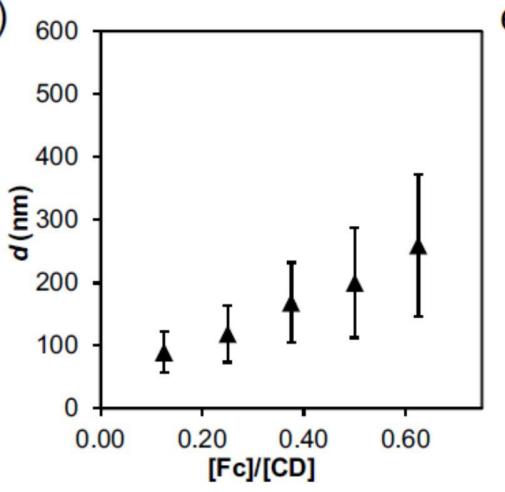

b)

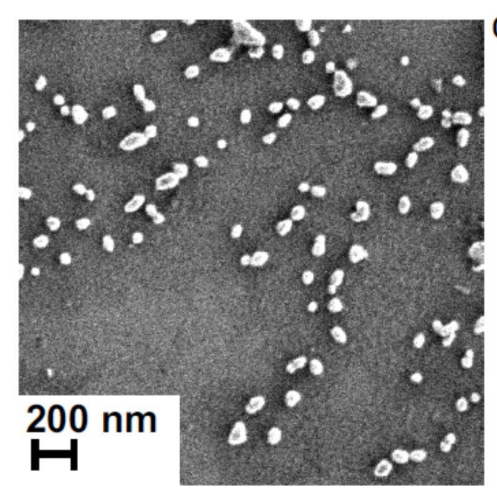

e)

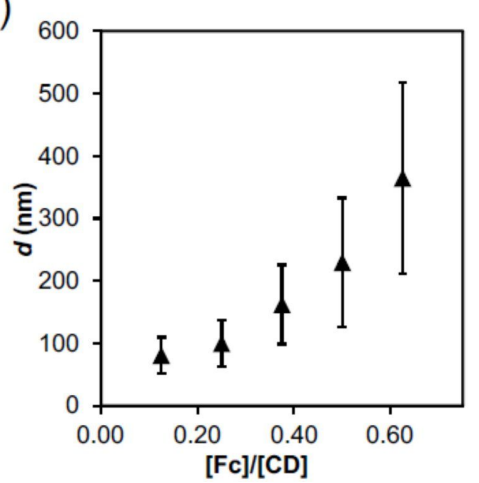

c)

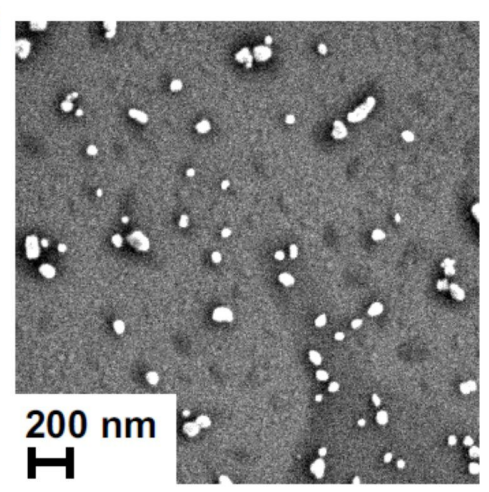

f)

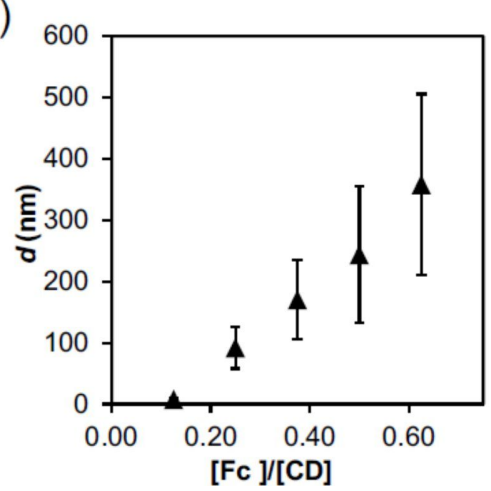

Figure 7: Size determinations of SNPs prepared from CD-PEI, Fc 8 -PAMAM and Ad-PEG: SEM images (a-c) of the resulting SNPs by increasing $[\mathrm{Fc}] /[\mathrm{CD}]$ ratios (in $\mathrm{Fc}$ and $\mathrm{CD}$ moieties from $\mathrm{Fc}_{8}$-PAMAM and $\mathrm{CD}-\mathrm{PEI}$, respectively) using $0.2 \mathrm{M} \mathrm{NaCl}$ (a: 0.375 , b: 0.50 and c: 0.625$)$ used during supramolecular assembly using $[C D]=100 \mu \mathrm{M}$ and $C D:(A d+F c)$ stoichiometry, and DLS data (d-f) after: d) $20 \mathrm{~min}, e) 4 \mathrm{~h}$ and f) 7 days. 


\section{Stimulus-responsive disassembly by oxidation}

The redox-triggered disassembly of the Fc-containing SNPs (see Scheme 1a) makes use of the redox-responsive properties of $\mathrm{Fc}$ and the resulting loss of binding affinity for $\mathrm{CD}$ upon oxidation of $\mathrm{Fc}$ to the ferrocenium cation. We chose $\mathrm{Ce}^{4+}$ as the oxidizing agent to perform the disassembly experiments because of its proven effectiveness in a $\mathrm{Fc} / \mathrm{CD}$ system similar to ours [30]. SNPs composed of CD-PEI, Fc $\mathrm{F}_{8}$-PAMAM and Ad-PEG were formed using a ratio of $\mathrm{CD} /(\mathrm{Ad}+\mathrm{Fc})=1: 1$. The hydrodynamic diameter $d$ by DLS was found to be $210 \mathrm{~nm}$. Directly thereafter, a small volume of a $\mathrm{Ce}^{4+}$ stock solution was injected into the sample $(\mathrm{Ce} / \mathrm{Fc}=10)$. The SNP size was then monitored by DLS over time as shown in Figure 8a before (red) and after addition of $\mathrm{Ce}^{4+}$ (green) at $10 \mathrm{~min}$. These results show a quick breakdown of the aggregates in the first $20 \mathrm{~min}$. Sizes measured thereafter resemble the size measured for CD-PEI only. To prove that particle disassembly requires the redoxactive $\mathrm{Fc}$ group, a similar experiment was performed using the redox-silent $\mathrm{Ad}_{8}$-PAMAM dendrimer (see Scheme 1a) as a control. SNPs composed of CD-PEI, Ad 8 -PAMAM and Ad-PEG were formed using $[\mathrm{CD}]=100 \mu \mathrm{M}(\mathrm{CD}$ is the number of moieties from CD-PEI), [Ad] $=37.5 \mu \mathrm{M}$ (Ad is the number of moieties coming from $\mathrm{Ad}_{8}$-PAMAM) and $[\mathrm{Ad}]=62.5 \mu \mathrm{M}$ (from Ad-PEG) in $0.2 \mathrm{M} \mathrm{NaCl}$. A size of $d \approx 150 \mathrm{~nm}$ was measured by DLS. Figure $8 \mathrm{~b}$ shows the hydrodynamic diameter of these aggregates over time before (red) and after addi- tion of $\mathrm{Ce}^{4+}$ (green) at $10 \mathrm{~min}$. These results shows that the Ad-based SNPs do not disassemble in the presence of oxidant. Therefore we conclude that $\mathrm{Fc}$ groups are needed to equip the SNPs with a triggered disassembly mechanism, attributed to the oxidation of the $\mathrm{Fc}$ groups of $\mathrm{Fc}_{8}$-PAMAM to the ferrocenium cation resulting in decomplexation of the guest groups and concomitant loss of multivalent links between the CD-PEI units in the SNPs.

\section{Conclusion}

In conclusion, we have developed a strategy to form supramolecular nanoparticles using a redox-active host-guest complex as the interaction motif. The size of the resulting nanoparticles was controlled by different parameters, and SNP disassembly was achieved by using oxidation of the redox-active Fc moiety as the trigger. For the first time, we have shown that using positively charged building blocks, the size and stability of the supramolecular nanoparticles depend on a balance between repulsive electrostatic interactions between the charged building blocks and attractive host-guest interactions between the multivalent guest-functionalized dendrimers and host-functionalized polymers. At higher ionic strengths, the increased charge screening led to a loss of electrostatic repulsion and therefore to larger aggregates. Optimal self-assembly of the multivalent components was observed at a 1:1 stoichiometry of the host/guest moieties. A stabilizer with high binding affinity and sufficient steric repulsion is needed to obtain stable and
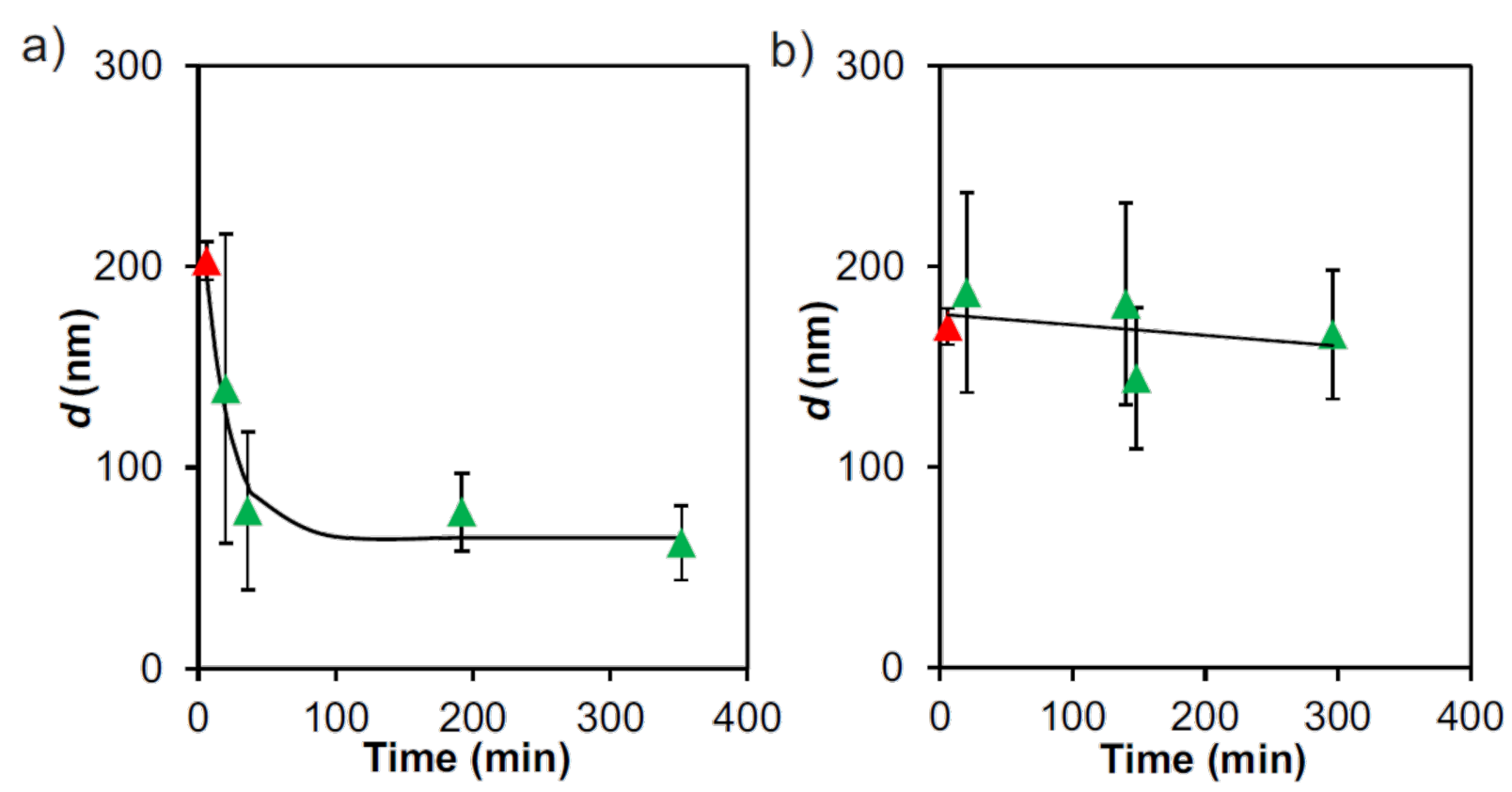

Figure 8: DLS size determination before (red) and after the addition of the oxidant agent $\mathrm{Ce}^{4+}$ (green) for as-prepared SNPs: a) $[C D]=100 \mu M$ (in $C D$ moieties from CD-PEI) [Fc] $=50 \mu \mathrm{M}$ (in Fc moieties from F $\mathrm{C}_{8}$-PAMAM) and [Ad] $=50 \mu \mathrm{M}$ (from Ad-PEG) and b) [CD] $=100 \mu \mathrm{M}$ and $[\mathrm{Ad}]=37.5 \mu \mathrm{M}$ (in Ad moieties from $\mathrm{Ad}_{8}$-PAMAM) and $[\mathrm{Ad}]=62.5 \mu \mathrm{M}$ (from Ad-PEG) (control) in $0.2 \mathrm{M} \mathrm{NaCl}$. 10 equiv of $\mathrm{Ce}^{4+}$ relative to Fc was added to the SNPs. Experimental $d$ measurements (markers) and trendlines (line, guide to the eye). 
small particles, thus Ad-PEG was observed to be the optimal stopper. Variation of the mono- to multivalent guest ratio provided a range of SNP sizes, and the SNPs were stable up to 7 days. The particles were successfully disassembled using a chemical oxidant. The understanding of the forces involved in SNP formation, and control over their stability and responsive character makes these SNPs a promising candidate for developing a drug delivery vehicle where control over the drug encapsulation and release can be achieved.

\section{Experimental Materials}

Reagents and solvents were purchased from Sigma-Aldrich and used as received without further purification, unless noted otherwise. Millipore water with a resistivity of $18.2 \mathrm{M} \Omega \mathrm{cm}$ at $25{ }^{\circ} \mathrm{C}$ was used in all the experiments. The amine-terminated poly(amido amine) dendrimer was purchased from Symo-Chem and received as a solution in methanol $(20 \% \mathrm{w} / \mathrm{w})$.

\section{Synthetic procedures}

The 6-monotosyl- $\beta$-cyclodextrin was synthesized according to a literature procedure [31]. The multivalent $\mathrm{Fc}_{8}$-PAMAM was prepared according to a procedure developed in our group [28]. Syntheses of $\mathrm{Ad}_{8}$-PAMAM and Ad-PEG $\left(M_{\mathrm{W}}=5000 \mathrm{~g} / \mathrm{mol}\right)$ were performed according to literature procedures [11], as well as Ad-TEG [32].

\section{Synthesis of CD-PEI}

The procedure for preparing the $\beta$-CD-functionalized PEI polymer was based on a literature procedure [11]. DMSO was freshly distilled under argon. Then, to a solution of branched poly(ethylene imine) $\left[M_{\mathrm{w}} \approx 10,000 \mathrm{~g} / \mathrm{mol}\right](250 \mathrm{mg}$, $0.025 \mathrm{mmol})$ dissolved in $45 \mathrm{~mL}$ DMSO under argon at $60{ }^{\circ} \mathrm{C}$, a solution of 6-monotosyl- $\beta$-cyclodextrin $(1.4 \mathrm{~g}, 1.1 \mathrm{mmol})$ and $0.5 \mathrm{~mL}$ triethylamine in $35 \mathrm{~mL}$ of DMSO was added slowly under argon by using a syringe while stirring. The resulting solution was stirred at $60{ }^{\circ} \mathrm{C}$ for three days under argon. The solution was cooled to room temperature and diluted with $40 \mathrm{~mL}$ deionized water with a resulting $\mathrm{pH}$ of 10.9. The solution was transferred to a Spectra/Por MWCO 6-8 kD membrane and dialyzed against water for 4 days. The dialyzed solutions were filtered over paper and lyophilized to afford $189 \mathrm{mg}$ of a fluffy, near-white solid. ${ }^{1} \mathrm{H}$ NMR $\left(400 \mathrm{MHz}, \mathrm{D}_{2} \mathrm{O}\right) \delta(\mathrm{ppm})$ 5.39-5.05 (br, 7H, C1H of CD), 3.87-3.56 (m, 42.1, C2-6H of $\mathrm{CD}), 3.5-2.2$ (br, 115.6, $\mathrm{OCH}_{2}$ of PEI).

\section{Synthesis of Fc-PEG}

Methoxypoly(ethylene glycol)amine $\left(M_{\mathrm{w}}=5000 \mathrm{~g} / \mathrm{mol}\right.$; $250 \mathrm{mg}, 0.050 \mathrm{mmol}$ ) and $0.2 \mathrm{~mL}$ triethylamine was dissolved in $15 \mathrm{~mL} \mathrm{CH} \mathrm{Cl}_{2}$ under argon in a $100 \mathrm{~mL}$ one-necked roundbottom flask. While stirring, a solution of ferrocenoyl chloride
(500 mg, $2.0 \mathrm{mmol}$ ) in $15 \mathrm{~mL}$ dichloromethane was added dropwise by using a syringe. The mixture was allowed to stir overnight at room temperature under argon. The solvent was removed leaving an orange residue. The residue was dissolved in $20 \mathrm{~mL}$ chloroform. The chloroform mixture was washed with $10 \mathrm{~mL}$ aqueous saturated $\mathrm{NaHCO}_{3}$ solution after which the organic layer was dried using $\mathrm{MgSO}_{4}$. After filtration over paper, the solvent was removed by evaporation and the remaining precipitate was redissolved in $2 \mathrm{~mL}$ chloroform. The chloroform solution was added dropwise to $40 \mathrm{~mL}$ of diethyl ether, giving immediate precipitation of a yellow solid, which was filtrated and dried in a vacuum oven at $40{ }^{\circ} \mathrm{C}$ overnight. This yielded $136 \mathrm{mg}$ of a slightly yellow solid. ${ }^{1} \mathrm{H}$ NMR $\left(400 \mathrm{MHz}, \mathrm{D}_{2} \mathrm{O}\right) \delta(\mathrm{ppm}) 4.78(\mathrm{~m}, 2 \mathrm{H}, \mathrm{Fc}), 4.53(\mathrm{t}, 2 \mathrm{H}, \mathrm{Fc})$, $4.28(\mathrm{~s}, 5 \mathrm{H}, \mathrm{Fc}), 3.85\left(\mathrm{t}, 2 \mathrm{H}, \mathrm{CH}_{2} \mathrm{CH}_{2} \mathrm{NHCO}\right), 3.50(\mathrm{t}, 2 \mathrm{H}$, $\left.\mathrm{CH}_{2} \mathrm{NHCO}\right), 3.36\left(\mathrm{~s}, 3 \mathrm{H}, \mathrm{OCH}_{3}\right)$.

\section{Methods}

\section{Supramolecular nanoparticle assembly as a function of ionic strength}

For the preparation of SNPs as a function of ionic strength $(0-0.2 \mathrm{M} \mathrm{NaCl})$, aqueous solutions of $\mathrm{CD}-\mathrm{PEI}$ and $\mathrm{NaCl}$ and $\mathrm{Fc}_{8}$-PAMAM in DMSO were prepared before mixing. The concentration of CD-PEI was kept constant. As an example, for preparing a solution of $50 \% \mathrm{Fc}$ entities derived from the $\mathrm{Fc}$ dendrimer in $0.1 \mathrm{M} \mathrm{NaCl}$, first $100 \mu \mathrm{L}$ of aqueous CD-PEI solution (500 $\mu \mathrm{M}$ in $\mathrm{CD}$ moieties), $60 \mu \mathrm{L}$ of aqueous $\mathrm{NaCl}$ solution $(833.3 \mathrm{mM})$ and $340 \mu \mathrm{L}$ of water were mixed for $30 \mathrm{~s}$. After mixing, $7.5 \mu \mathrm{L}$ of $\mathrm{Fc}_{8}$-PAMAM solution in DMSO $(3336 \mu \mathrm{M}$ in Fc moieties) was injected to the previous solution while sonicating.

\section{Job plot using $\mathrm{FC}_{8}$-PAMAM}

For the preparation of SNPs using $0.4 \mathrm{M} \mathrm{NaCl}$, an aqueous solution of $\mathrm{CD}-\mathrm{PEI}$, free $\mathrm{CD}, \mathrm{NaCl}$ and a solution of $\mathrm{Fc}_{8}-$ PAMAM in DMSO were prepared before mixing. The concentration of total moieties was kept constant at $50 \mu \mathrm{M}$. As an example, for preparing a solution of $50 \% \mathrm{Fc}$ entities $(25 \mu \mathrm{M})$ derived from the $\mathrm{Fc}$ dendrimer, first $125 \mu \mathrm{L}$ of aqueous $\mathrm{CD}-\mathrm{PEI} /$ free $\mathrm{CD}$ solution $(100 \mu \mathrm{M}$ in CD moieties; $2 \mathrm{mM}$ free $\mathrm{CD}), 240 \mu \mathrm{L}$ of aqueous $\mathrm{NaCl} /$ free $\mathrm{CD}$ solution $(833.3 \mathrm{mM}$ $\mathrm{NaCl} ; 2 \mathrm{mM}$ free $\mathrm{CD}$ ) and $135 \mu \mathrm{L}$ of aqueous free $\mathrm{CD}$ solution $(2 \mathrm{mM})$, were mixed for $30 \mathrm{~s}$. After mixing, $7.5 \mu \mathrm{L}$ of $\mathrm{Fc}_{8}-$ PAMAM solution in DMSO (1664 $\mu \mathrm{M}$ in Fc moieties) was injected to the previous solution while sonicating.

\section{Job plot using $\mathrm{Ad}_{8}$-PAMAM}

For the preparation of SNPs using $0.2 \mathrm{M} \mathrm{NaCl}$, aqueous solution of CD-PEI, free $\mathrm{CD}, \mathrm{NaCl}$ and solution of $\mathrm{Ad}_{8}$-PAMAM in DMSO were prepared before mixing. The concentration of total moieties was kept constant at $200 \mu \mathrm{M}$. As an example, for pre- 
paring a solution of $50 \%$ Ad entities $(100 \mu \mathrm{M})$ derived from the Ad dendrimer, first $125 \mu \mathrm{L}$ of aqueous CD-PEI/free CD solution $(400 \mu \mathrm{M}$ in $\mathrm{CD}$ moieties; $2 \mathrm{mM}$ free $\mathrm{CD}), 120 \mu \mathrm{L}$ of aqueous $\mathrm{NaCl} /$ free $\mathrm{CD}$ solution ( $833.3 \mathrm{mM} \mathrm{NaCl} ; 2 \mathrm{mM}$ free $\mathrm{CD})$ and $255 \mu \mathrm{L}$ of aqueous free $\mathrm{CD}$ solution $(2 \mathrm{mM})$, were mixed for $30 \mathrm{~s}$. After mixing, $7.5 \mu \mathrm{L}$ of $\mathrm{Ad}_{8}$-PAMAM solution in DMSO (6664 $\mu \mathrm{M}$ in Ad moieties) was injected to the previous solution while sonicating.

\section{Supramolecular nanoparticle assembly as a function of different stoppers}

For the preparation of SNPs using $0.2 \mathrm{M} \mathrm{NaCl}$ as a function of stoppers at two different $\mathrm{Fc}$ fractions, various aqueous solutions of CD-PEI, PEG modified (Ad-TEG, Ad-PEG $\left(M_{\mathrm{w}}=5000 \mathrm{~g} / \mathrm{mol}\right)$, Fc-PEG $\left(M_{\mathrm{w}}=5000 \mathrm{~g} / \mathrm{mol}\right), \mathrm{mPEG}$ $\left(M_{\mathrm{W}}=5000 \mathrm{~g} / \mathrm{mol}\right)$ and using two different concentrations of $\mathrm{Fc}_{8}$-PAMAM in DMSO were prepared. The concentration of CD-PEI was kept the same. As an example, for preparing a solution of $50 \% \mathrm{Fc}$ entities derived from the Fc dendrimer using Ad-PEG, first $100 \mu \mathrm{L}$ of aqueous CD-PEI solution $(500 \mu \mathrm{M}$ in CD moieties), $100 \mu \mathrm{L}$ of aqueous Ad-PEG solution $(250 \mu \mathrm{M})$, $120 \mu \mathrm{L}$ of aqueous $\mathrm{NaCl}$ solution $(833.3 \mathrm{mM})$ and $180 \mu \mathrm{L}$ of DI water were mixed for $30 \mathrm{~s}$. After mixing, $7.5 \mu \mathrm{L}$ of $\mathrm{Fc}_{8}$ PAMAM solution in DMSO (3336 $\mu \mathrm{M}$ in Fc moieties) was injected to the previous solution while sonicating.

\section{Supramolecular nanoparticle assembly as a function of increasing multivalent guest}

For the preparation of SNPs in $0.2 \mathrm{M} \mathrm{NaCl}$ various aqueous solution of CD-PEI and Ad-PEG and $\mathrm{Fc}_{8}$-PAMAM in DMSO were prepared before mixing. The concentration of CD-PEI was kept the same. As an example, preparing a solution of $50 \% \mathrm{Fc}$ entities derived from the $\mathrm{Fc}$ dendrimer, first $100 \mu \mathrm{L}$ of aqueous CD-PEI solution (500 $\mu \mathrm{M}$ in CD moieties), $100 \mu \mathrm{L}$ of aqueous Ad-PEG solution $(250 \mu \mathrm{M}), 120 \mu \mathrm{L}$ of aqueous $\mathrm{NaCl}$ solution $(833.3 \mathrm{mM})$ and $180 \mu \mathrm{L}$ of DI-water were mixed for $30 \mathrm{~s}$. After mixing, $7.5 \mu \mathrm{L}$ of $\mathrm{Fc}_{8}$-PAMAM solution in DMSO (3336 $\mu \mathrm{M}$ in Fc moieties) was injected to the previous solution while sonicating.

\section{Triggered disassembly of SNPs}

To evaluate the redox responsiveness of the particles, SNPs containing $[\mathrm{CD}]=100 \mu \mathrm{M}$ (in $\mathrm{CD}$ moieties from CD-PEI), $[\mathrm{Fc}]=50 \mu \mathrm{M}$ (in Fc from $\mathrm{Fc}_{8}-\mathrm{PAMAM}$ ) and $[\mathrm{Ad}]=50 \mu \mathrm{M}$ (from Ad-PEG) were prepared in $0.4 \mathrm{M} \mathrm{NaCl}$ solution. The $d$ was measured over time after the injection of $\mathrm{Ce}^{4+}(10$ equiv of $\mathrm{Ce}^{4+}$ relative to $\mathrm{Fc}$ was added to the SNPs). To evaluate whether the SNP disassembly was due to the oxidation of the ferrocene groups, SNPs containing $[\mathrm{CD}]=100 \mu \mathrm{M}$ (in $\mathrm{CD}$ moieties from CD-PEI), [Ad] $=37.5 \mu \mathrm{M}$ (in Ad from $\mathrm{Ad}_{8}$ $\mathrm{PAMAM}$ ) and $[\mathrm{Ad}]=62.5 \mu \mathrm{M}$ (from Ad-PEG) were prepared in $0.2 \mathrm{M} \mathrm{NaCl}$. The $d$ was measured over time after the injection of $\mathrm{Ce}^{4+}$ (10 equiv of $\mathrm{Ce}^{4+}$ relative to Ad was added to the SNPs).

\section{Equipment \\ Dynamic light scattering (DLS)}

Hydrodynamic diameters and zeta potentials were measured on a Zetasizer NanoZS (Malvern Instrument Ltd, Malvern, United Kingdom) at $20^{\circ} \mathrm{C}$, with a laser wavelength of $633 \mathrm{~nm}$ and a scattering angle of $173^{\circ}$.

\section{High resolution scanning electron microscopy (HR-SEM)}

All SEM images were taken with a Carl Zeiss Merlin scanning electron microscope. The samples were prepared by dropcasting $10 \mu \mathrm{L}$ of a SNP solution onto a silicon wafer. After $60 \mathrm{~s}$, excess of water was removed by filter paper. The particle dimensions are obtained from SEM images with ImageJ software. For each sample at least 100 particles were measured.

\section{Calorimetric analysis}

Calorimetric titrations were performed at $25{ }^{\circ} \mathrm{C}$ using a Microcal VP-ITC titration microcalorimeter. Sample solutions were prepared in Millipore water.

\section{NMR spectroscopy}

${ }^{1} \mathrm{H}$ NMR spectra was recorded on a Bruker $400 \mathrm{MHz}$ NMR spectrometer. ${ }^{1} \mathrm{H}$ chemical shift value, $400 \mathrm{MHz}$ is reported as $\delta$ using the residual solvent signal as internal standard at $\approx 22^{\circ} \mathrm{C}$.

\section{Mass spectrometry}

Mass analysis was done using matrix-assisted laser desorption ionization (MALDI) on a Waters Synapt G1 using 2,5-dihydroxybenzoic acid as the matrix.

\section{Acknowledgements}

This research was supported by the Council for Chemical Sciences of the Netherlands Organization for Scientific Research (NWO-CW, Vici grant 700.58.443 to J.H.). We gratefully thank Laura Grana Suarez for the synthesis of $\mathrm{Ad}_{8}-$ PAMAM and Ad-PEG, Carmen Stoffelen for the synthesis of Ad-TEG, and Regine Van der Hee for the mass measurements. Alejandro Mendez Ardoy and Rian Ruhl are acknowledged for their help and fruitful discussions and Mark A. Smithers for HR-SEM imaging.

\section{References}

1. Chen, K.-J.; Garcia, M. A.; Wang, H.; Tseng, H.-R. Supramolecular Chemistry; John Wiley \& Sons, Ltd, 2012; pp 1-16.

2. Stoffelen, C.; Huskens, J. Chem. Commun. 2013, 49, 6740-6742. doi: $10.1039 / \mathrm{c} 3 \mathrm{cc} 43045 f$ 
3. Chen, K.-J.; Wolahan, S. M.; Wang, H.; Hsu, C.-H.; Chang, H.-W.; Durazo, A.; Hwang, L.-P.; Garcia, M. A.; Jiang, Z. K.; Wu, L.; Lin, Y.-Y.; Tseng, H.-R. Biomaterials 2011, 32, 2160-2165. doi:10.1016/j.biomaterials.2010.11.043

4. Wang, S. T.; Chen, K. J.; Wu, T. H.; Wang, H.; Lin, W. Y.; Ohashi, M.; Chiou, P. Y.; Tseng, H.-R. Angew. Chem., Int. Ed. 2010, 49, 3777-3781. doi:10.1002/anie.201000062

5. Chen, K.-J.; Tang, L.; Garcia, M. A.; Wang, H.; Lu, H.; Lin, W.-Y.; Hou, S.; Yin, Q.; Shen, C. K. F.; Cheng, J.; Tseng, H.-R. Biomaterials 2012, 33, 1162-1169. doi:10.1016/j.biomaterials.2011.10.044

6. Lee, J.-H.; Chen, K.-J.; Noh, S.-H.; Garcia, M. A.; Wang, H.; Lin, W.-Y.; Jeong, H.; Kong, B. J.; Stout, D. B.; Cheon, J.; Tseng, H.-R. Angew. Chem., Int. Ed. 2013, 52, 4384-4388. doi:10.1002/anie.201207721

7. Liu, Y.; Wang, H.; Kamei, K.-i.; Yan, M.; Chen, K.-J.; Yuan, Q.; Shi, L.; Lu, Y.; Tseng, H.-R. Angew. Chem., Int. Ed. 2011, 50, 3058-3062. doi:10.1002/anie.201005740

8. Davis, M. E. Mol. Pharmaceutics 2009, 6, 659-668. doi:10.1021/mp900015y

9. Wang, H.; Chen, K.-J.; Wang, S.; Ohashi, M.; Kamei, K.-i.; Sun, J.; Ha, J. H.; Liu, K.; Tseng, H.-R. Chem. Commun. 2010, 46, 1851-1853. doi:10.1039/b923711a

10. Wang, H.; Liu, K.; Chen, K. J.; Lu, Y. J.; Wang, S. T.; Lin, W. Y.; Guo, F.; Kamei, K. I.; Chen, Y. C.; Ohashi, M.; Wang, M. W.; Garcia, M. A.; Zhao, X. Z.; Shen, C. K. F.; Tseng, H. R. ACS Nano 2010, 4, 6235-6243. doi:10.1021/nn101908e

11. Wang, H.; Wang, S.; Su, H.; Chen, K.-J.; Armijo, A. L.; Lin, W.-Y.; Wang, Y.; Sun, J.; Kamei, K.-i.; Czernin, J.; Radu, C. G.; Tseng, H.-R. Angew. Chem., Int. Ed. 2009, 48, 4344-4348. doi:10.1002/anie.200900063

12. Mejia-Ariza, R.; Huskens, J. J. Mater. Chem. B 2014, 2, 210-216. doi:10.1039/C3TB21228A

13. Wintgens, V.; Nielsen, T. T.; Larsen, K. L.; Amiel, C. Macromol. Biosci. 2011, 11, 1254-1263. doi:10.1002/mabi.201100097

14. Stoffelen, C.; Munirathinam, R.; Verboom, W.; Huskens, J. Mater. Horiz. 2014, 1, 595-601. doi:10.1039/C4MH00103F

15. Stoffelen, C.; Voskuhl, J.; Jonkheijm, P.; Huskens, J. Angew. Chem., Int. Ed. 2014, 53, 3400-3404. doi:10.1002/anie.201310829

16. Grana Suarez, L.; Verboom, W.; Huskens, J. Chem. Commun. 2014, 50, 7280-7282. doi:10.1039/C4CC03136A

17. Harada, A.; Takahashi, S. J. Inclusion Phenom. 1984, 2, 791-798. doi:10.1007/BF00662247

18. Kaifer, A. E. Acc. Chem. Res. 1998, 32, 62-71. doi:10.1021/ar970335u

19. Nakahata, M.; Takashima, Y.; Yamaguchi, H.; Harada, A. Nat. Commun. 2011, 2, 511. doi:10.1038/ncomms1521

20. Nakahata, M.; Takashima, Y.; Harada, A. Angew. Chem., Int. Ed. 2014 53, 3617-3621. doi:10.1002/anie.201310295

21. Du, P.; Liu, J.; Chen, G.; Jiang, M. Langmuir 2011, 27, 9602-9608. doi:10.1021/la201843z

22. Yan, Q.; Yuan, J.; Cai, Z.; Xin, Y.; Kang, Y.; Yin, Y. J. Am. Chem. Soc. 2010, 132, 9268-9270. doi:10.1021/ja1027502

23. de laRica, R.; Fratila, R. M.; Szarpak, A.; Huskens, J.; Velders, A. H. Angew. Chem., Int. Ed. 2011, 50, 5704-5706. doi:10.1002/anie.201008189

24. Lee, D.-W.; Park, K. M.; Banerjee, M.; Ha, S. H.; Lee, T.; Suh, K.; Paul, S.; Jung, H.; Kim, J.; Selvapalam, N.; Ryu, S. H.; Kim, K. Nat. Chem. 2011, 3, 154-159. doi:10.1038/nchem.928
25. Pun, S. H.; Bellocq, N. C.; Liu, A.; Jensen, G.; Machemer, T.; Quijano, E.; Schluep, T.; Wen, S.; Engler, H.; Heidel, J.; Davis, M. E. Bioconjugate Chem. 2004, 15, 831-840. doi:10.1021/bc049891g

26. Shen, J.; Kim, H.-C.; Su, H.; Wang, F.; Wolfram, J.; Kirui, D.; Mai, J.; Mu, C.; Ji, L.-N.; Mao, Z.-W.; Shen, H. Theranostics 2014, 4, 487-497. doi:10.7150/thno.8263

27. Nijhuis, C. A.; Yu, F.; Knoll, W.; Huskens, J.; Reinhoudt, D. N. Langmuir 2005, 21, 7866-7876. doi:10.1021/la051156l

28. Nijhuis, C. A.; Huskens, J.; Reinhoudt, D. N. J. Am. Chem. Soc. 2004, 126, 12266-12267. doi:10.1021/ja048271n

29. Lu, J.; Huang, Y.; Zhao, W.; Marquez, R. T.; Meng, X.; Li, J.; Gao, X.; Venkataramanan, R.; Wang, Z.; Li, S. Biomaterials 2013, 34, 1591-1600. doi:10.1016/j.biomaterials.2012.10.073

30. Nakahata, M.; Takashima, Y.; Hashidzume, A.; Harada, A. Angew. Chem., Int. Ed. 2013, 52, 5731-5735. doi:10.1002/anie.201300862

31. Djedaini-Pilard, F.; Gosnat, M.; Steinbruckner, S.; Dalbiez, J. P.; Crini, G.; Perly, B.; Gadelle, A. In Proceedings of the Ninth International Symposium on Cyclodextrins, Santiago de Compostela, Spain, May 31-June 3, 1998; Labandeira, J. J. T.; Vila-Jato, J. L., Eds.; Springer: Netherlands, 1999; pp 73-76.

32. Mulder, A.; Onclin, S.; Péter, M.; Hoogenboom, J. P.; Beijleveld, H.; ter Maat, J.; García-Parajó, M. F.; Ravoo, B. J.; Huskens, J.; van Hulst, N. F.; Reinhoudt, D. N. Small 2005, 1, 242-253. doi:10.1002/smll.200400063

\section{License and Terms}

This is an Open Access article under the terms of the Creative Commons Attribution License (http://creativecommons.org/licenses/by/2.0), which permits unrestricted use, distribution, and reproduction in any medium, provided the original work is properly cited.

The license is subject to the Beilstein Journal of Organic Chemistry terms and conditions:

(http://www.beilstein-journals.org/bjoc)

The definitive version of this article is the electronic one which can be found at: $\underline{\text { doi:10.3762/bjoc. } 11.260}$ 